\title{
Condições de circulação do Sistema Aquífero Guarani no estado de Goiás
}

\author{
Luiz Antônio de Oliveira ${ }^{1 *}$, José Eloi Guimarães Campos ${ }^{2}$
}

\begin{abstract}
Resumo O objetivo principal deste trabalho foi propor modelos conceituais de fluxo para o Sistema Aquífero Guarani em sua área de ocorrência no estado de Goiás, no Brasil. Na área de estudo, o sistema aquífero é composto por arenitos eólicos de idade jurássica da Formação Botucatu, sendo o regional com maior potencial quantitativo. No estado de Goiás ocupa uma área de $44.000 \mathrm{~km}^{2}$, destes, $9.580 \mathrm{~km}^{2}$ são áreas de afloramento e $35.138 \mathrm{~km}^{2}$ representam as porções confinadas pelos basaltos da Formação Serra Geral. Com base em dados geológicos, isotópicos e hidroquímicos, foram propostos modelos de fluxo para o Sistema Aquífero Guarani no estado de Goiás. Nas áreas de afloramento foram considerados dois subtipos distintos de aquíferos relacionados aos modelos tipos intergranular livre e livre de dupla porosidade. Nas áreas de confinamento foram considerados três subtipos que incluem aquífero totalmente confinado e aquífero semiconfinado, com e sem contribuição de água armazenada no aquitarde. Os modelos conceituais dos aquíferos são essenciais para o entendimento dos padrões de fluxo, quimismo das águas, simulações matemática e numérica e gestão e determinação do potencial quantitativo dos reservatórios subterrâneos.
\end{abstract}

Palavras-chave: aquífero totalmente confinado; dupla porosidade; aquífero semiconfinado; Aquífero Guarani; estado de Goiás.

\begin{abstract}
Conceptual flow models of the Guarani aquifer system in Goiás state, Brazil. The main objective of this work was the proposition of aquifer conceptual models of the Guarani Aquifer System in the state of Goiás, Brazil. In the research area, the aquifer system is composed by aeolian sandstone Jurassic age of the Botucatu Formation, and it is considered the most important aquifer in terms of regional quantitative potential. In the state of Goiás, it occupies an area of $44,000 \mathrm{~km}^{2}$, of this, $9,580 \mathrm{~km}^{2}$ are outcrops areas and $35,138 \mathrm{~km}^{2}$ represent confined portions by the basalts of the Serra Geral Formation. On the basis of geologic, isotopic, and hydrochemistry data, different models of groundwater flow were proposed for the Guarani Aquifer System in the state of Goiás. In the outcrop areas, two distinct aquifers subtypes were considered: the unconfined intergranular and the double porosity unconfined. In the confining areas, three subtypes could be listed including the fully confined aquifer and the semiconfined with and without storage in the aquitard. The conceptual models of the aquifers are essential for understanding the flow patterns, mathematical and numerical simulation, management and determination of the quantitative potential of the groundwater reservoirs.
\end{abstract}

Keywords: fully confined aquifer; double porosity; semiconfined aquifer; Guarani Aquifer; Goiás state.

INTRODUÇÃO Este trabalho apresenta parte dos resultados de uma pesquisa de tese de doutorado que objetivou a caracterização do Sistema Aquífero Guarani no estado de Goiás, também trata especificamente do capítulo sobre as condições de circulação da água subterrânea no referido aquífero. Desta forma, a maioria das informações apresentadas expressa os resultados das pesquisas realizadas pelos autores em contraste com aqueles publicados.

O Sistema Aquífero Guarani é o maior reservatório subterrâneo transfronteiriço do Brasil e conta com um amplo acervo de informações em suas diversas áreas de ocorrência (Araújo et al. 1995, Rocha 1996, Dias et al. 2002, Gastmans \& Kiang 2005, Gastmans 2007, Rosa Filho 2004). Entretanto, em Goiás, o conhecimento deste ainda é muito limitado. Os dados mais atualizados mostram que muitas das características encontradas em outras áreas de ocorrência são comuns ao território goiano (variações dos valores de condutividade hidráulica e transmissividade, de espessuras dos arenitos e da camada confinante, dentre outros aspectos). Por outro lado, existem algumas diferenças marcantes como o fato de ser exclusivamente formado por arenitos da Formação Botucatu (ausência de outras unidades que compõem o aquífero em outras regiões), compartimentação tectônica particular, maior salinização das águas (na região de Cachoeira Dourada de Goiás) e idades contrastantes das águas.

Os limites laterais do Sistema Aquífero Guarani em Goiás foram recentemente detalhados por Oliveira (2009) e concluíram na retração da área da porção confinada, fato que foi anteriormente proposto por Araújo et al. (1995), resultando também numa redução da área total do aquífero no estado (Fig. 1). Em Goiás, o Sistema Aquífero Guarani

\footnotetext{
${ }^{1}$ Instituto de Geografia, Universidade Federal de Uberlândia - UFU, Uberlândia (MG), Brasil. E-mail: luiz_ao@yahoo.com.br ${ }^{2}$ Instituto de Geociências, Universidade de Brasília - UnB, Brasília (DF), Brasil. E-mail: eloi@unb.br

*Autor correspondente
} 


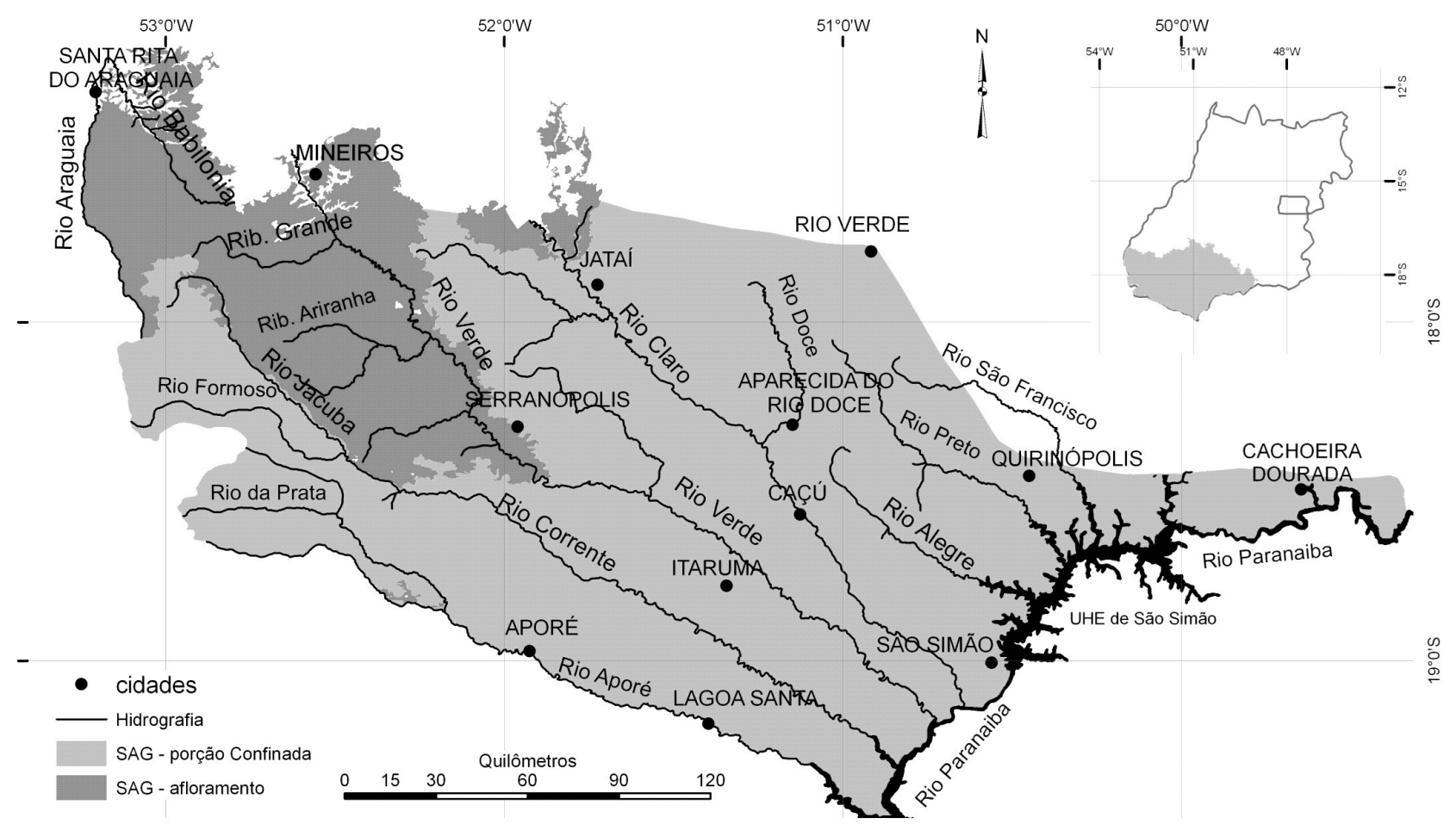

Figura 1 - Mapa de distribuição lateral do Sistema Aquifero Guarani (SAG) no estado de Goiás e localização das sedes dos principais municípios. Fonte: Oliveira 2009.

está distribuído por uma área de $44.718 \mathrm{~km}^{2}$. As zonas aflorantes somam $9.580 \mathrm{~km}^{2}$ e a porção confinada ocupa $35.138 \mathrm{~km}^{2}$.

No mesmo estado, devido ao fato de o aquífero estar, em parte, sotoposto a espessos derrames de basalto, a continuidade do conjunto é controlada pela tectônica da borda da bacia. O regime tafrogênico pré- e pós-basalto é um dos principais controles, tanto da presença ou ausência dos arenitos quanto de sua espessura (Oliveira 2009).

Correlacionando as formações geológicas com as idades relativas e baseando-se em dados levantados em perfis de poços tubulares profundos, é possível estabelecer que, no Triássico/Jurássico, a disposição da área de deposição foi controlada pelos contornos do embasamento cristalino, aflorantes na época mencionada. A região entre Quirinópolis e Itumbiara, posicionada a leste da área estudada, constituía-se em altos de embasamento, feição esta que limitou o avanço, sentido norte, dos depósitos areníticos. Por outro modo, a porção oeste, que engloba as atuais zonas aflorantes das regiões de Mineiros e Jataí, era uma área topograficamente deprimida e permitia o avanço da sedimentação da Formação Botucatu, sentido NW, avançando até o limite com o estado do Mato Grosso (Fig. 2).

Nos blocos elevados, antes da deposição do basalto, os arenitos da Formação Botucatu foram em parte ou integralmente erodidos como é o caso das regiões posicionadas a norte da região entre Rio Verde e Quirinópolis. Nos blocos tectonicamente deprimidos, como na região de afloramento de Jataí ou de baixo confinamento de Lagoa Santa, os arenitos apresentaram a maior espessura preservada (Oliveira 2009). Os grandes lineamentos da bacia, materializados pelos vales dos rios retilíneos com direção geral $\mathrm{N} 60^{\circ} \mathrm{W}$, representam as principais estruturas (por exemplo, os rios Claro, Verde, Corrente, Aporé e Doce). Neste contexto, a depressão tectônica associada ao lineamento do rio Paranaíba, denominada de DTRP, extensão nordeste do lineamento do rio Paraná, com direção geral $\mathrm{N} 45^{\circ} \mathrm{E}$, representa o par conjugado de tais lineamentos que controlam os sistemas regionais de fluxo hidrogeológico.

Os ambientes deposicionais da Formação Botucatu são coerentes com um sistema desértico com fácies de dunas e interdunas amplamente dominantes e com fácies de evaporitos, associadas a lagos de playa em paleoambientes restritos, atualmente observados nas vizinhanças das cidades de Cachoeira Dourada de Goiás e Cachoeira Dourada de Minas.

\section{RESULTADOS E DISCUSSÃO}

Modelos conceituais de fluxo Os modelos conceituais de fluxo são importantes para realização de 


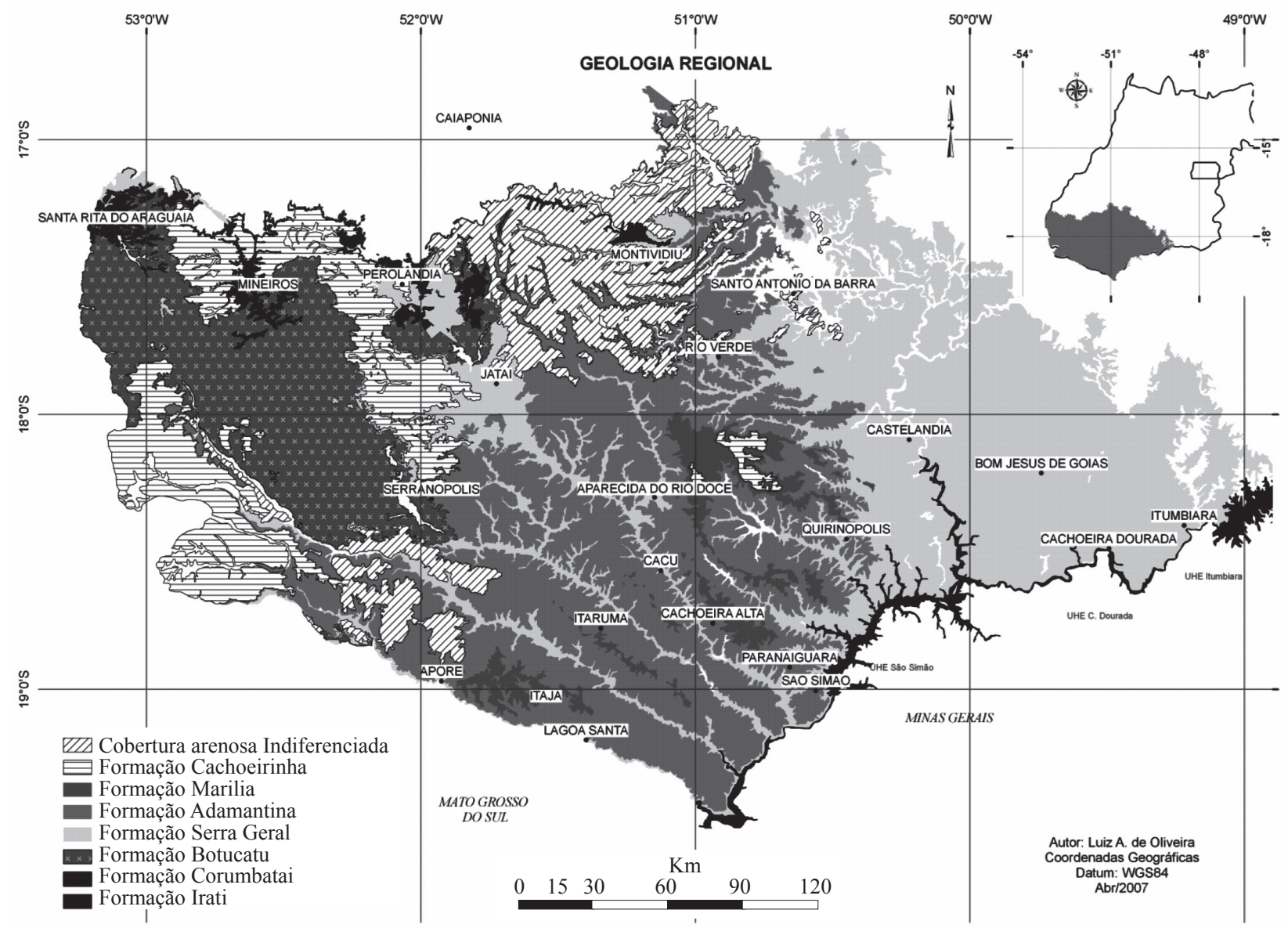

Figura 2 - Mapa geológico da área de estudos.

estudos hidráulicos e modelagem matemática, visando vários objetivos desde a caracterização até a gestão dos sistemas aquíferos. A escolha de um modelo conceitual adequado é fundamental para a determinação dos parâmetros hidrodinâmicos a partir dos dados de ensaios de bombeamento, para os estudos de recarga do aquífero, de fluxo de contaminantes e migração de plumas de contaminação, para a determinação de vazões outorgáveis, dentre outros aspectos.

Por outro lado, o uso do modelo conceitual inadequado pode resultar em modelos matemáticos incorretos, parâmetros hidráulicos sub ou superestimados, cálculos de rebaixamentos sub ou superestimados e erros na determinação do potencial quantitativo do aquífero.

A proposição dos modelos conceituais de fluxo para o Aquífero Guarani em Goiás foi realizada com base nos dados de geologia (de superfície e subsuperfície), hidroquímica, potenciometria, isótopos e clorofluorcarbonos - CFCs (obtidos em território goiano), além daqueles obtidos em outras áreas de ocorrência do aquífero nas cidades fronteiriças com o estado, localizadas no Mato Grosso do Sul e em
Minas Gerais. Com base em tais informações, são propostos cinco modelos de fluxo dentro do Sistema Aquífero Guarani, no estado de Goiás, incluindo aquíferos livres e confinados. Quando livres, dois casos são possíveis: aquífero intergranular e de dupla porosidade; quando confinados, três são as possibilidades: aquífero totalmente confinado, semiconfinado sem contribuição de água de armazenamento do aquitarde e semiconfinado com contribuição de água armazenada no aquitarde.

Aquífero livre intergranular Corresponde às zonas de afloramento nas quais os arenitos da Formação Botucatu não se apresentam cimentados e, por isso, em grande parte são friáveis mesmo em profundidade maior que $100 \mathrm{~m}$. A região de Jataí pode ser citada como um exemplo de ocorrência deste modelo de fluxo.

Neste caso, o aquífero pode ser considerado homogêneo e isotrópico, com fluxo do tipo laminar e responde hidraulicamente ao modelo de Neuman (1972 e 1975). A superfície potenciométrica coincide com a superfície freática da água, e a pressão hidrostática é igual à atmosférica (Fig. 3). 


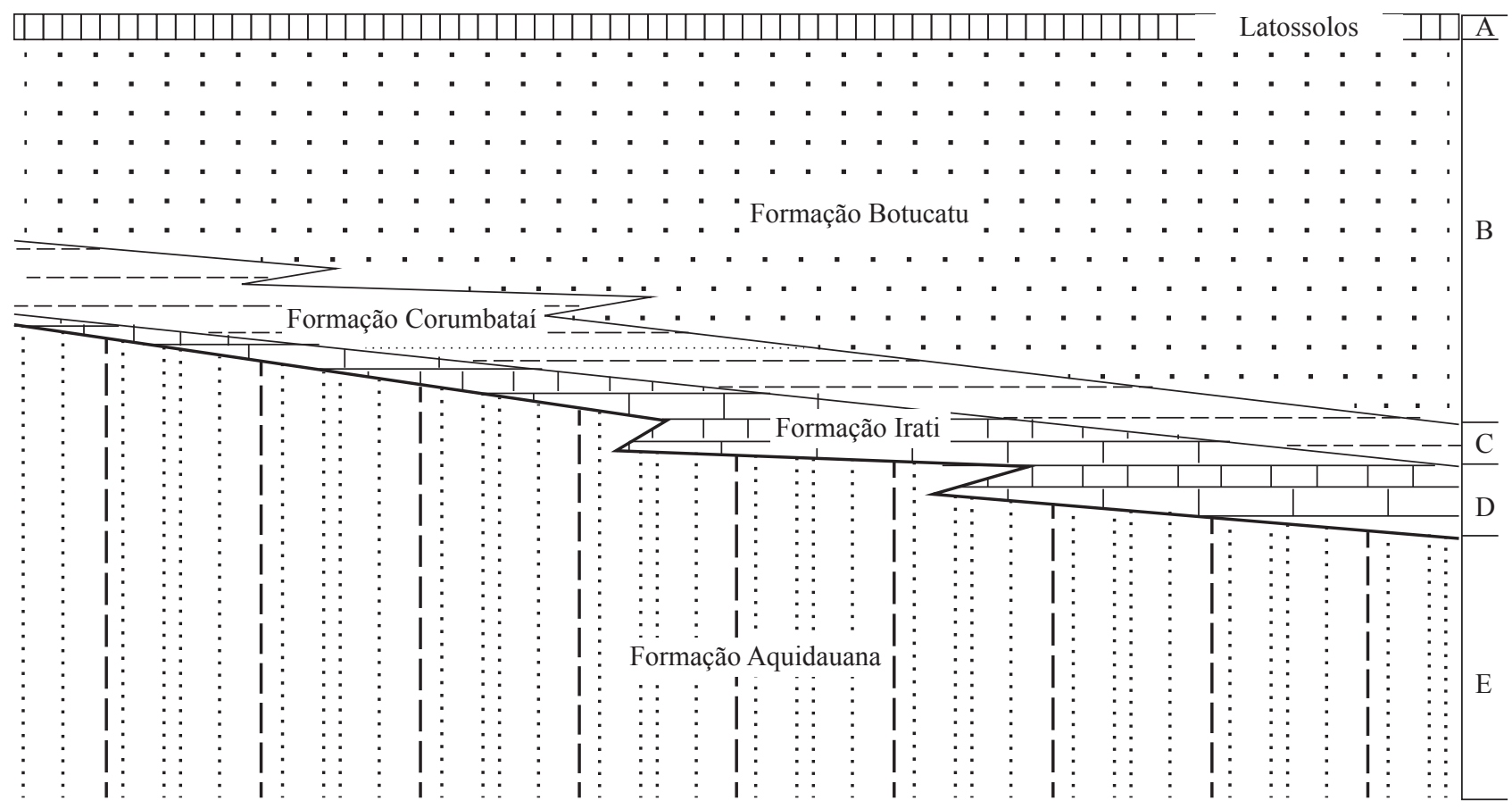

Figura 3 -Modelo conceitual do Sistema Aquifero Guarani (SAG) tipo intergranular livre que ocorre na região de Jataí. (A) material de cobertura composto por latossolos com espessura máxima de $20 \mathrm{~m}$; (B) Formação Botucatu, aquífero tipo intergranular, com espessura variando de 20 a 120 m; (C) Formação Corumbatai com espessura de até $80 \mathrm{~m}$ com descontinuidade lateral; (D) Formação Irati com espessura inferior a $40 \mathrm{~m}$; (E) Formação Aquidanana com espessura superior a $200 \mathrm{~m}$.

A base do aquífero é representada por unidades pouco permeáveis representadas por folhelhos e siltitos argilosos (Formação Corumbataí), calcários micríticos intercalados com folhelhos (Formação Irati) e arenitos finos argilosos ou calcíticos e diamictitos (Formação Aquidauana).

Os parâmetros hidrodinâmicos são compatíveis com este tipo de aquífero com destaque para a condutividade média da ordem de $10^{-5} \mathrm{~m} / \mathrm{s}$ (Almeida et al. 2006), que não varia muito espacialmente. O coeficiente de armazenamento varia em torno de 10 a 15.

$\mathrm{O}$ enquadramento de porções do sistema aquífero neste modelo de fluxo foi facilmente alcançado pelas descrições de afloramentos e amostras obtidas da perfuração de poços. Os dados hidrodinâmicos obtidos dos dados de ensaios de bombeamento também corroboram o modelo proposto.

Em tais áreas o relevo é plano a suave ondulado, e os solos arenosos são predominantes. Portanto, a recarga é facilitada, o que está de acordo com a grande vazão específica da drenagem superficial alimentada pelo seu fluxo de base. A concentração de sólidos totais dissolvidos (STD) dessas águas é inferior a $100 \mathrm{mg} / \mathrm{L}$.

Aquífero livre de dupla porosidade Também está associado a áreas de exposição da Formação
Botucatu, entretanto neste caso os arenitos são fortemente litificados pela ampla cimentação por sílica. O cimento, do tipo sílica amorfa e microcristalina, resulta na diminuição da porosidade primária. Em função da maior litificação, o conjunto sofre maior influência do fraturamento, portanto, responde a um modelo hidráulico do tipo dupla porosidade, com espaço matricial não superior a 2 ou $3 \%$ e porosidade secundária planar.

Na base, o aquífero é limitado por arenitos argilosos e litificados e lamitos da Formação Corumbataí, que, por apresentarem grande contraste de condutividade hidráulica com relação aos arenitos sobrepostos, podem ser considerados como camada impermeável ou um aquiclude (Fig. 4).

A região considerada típica, onde este modelo ocorre, engloba parte da área de afloramentos da região de Mineiros (municípios de Santa Rita do Araguaia, Mineiros e Serranópolis).

Como no caso dos aquíferos livres intergranulares, a superfície potenciométrica coincide com o nível freático da água; contudo, sua continuidade lateral é menos evidente, sendo controlada por blocos tectonicamente deslocados. Assim, podem ser observados níveis com diferentes cargas hidráulicas por elevação em poços relativamente próximos. 


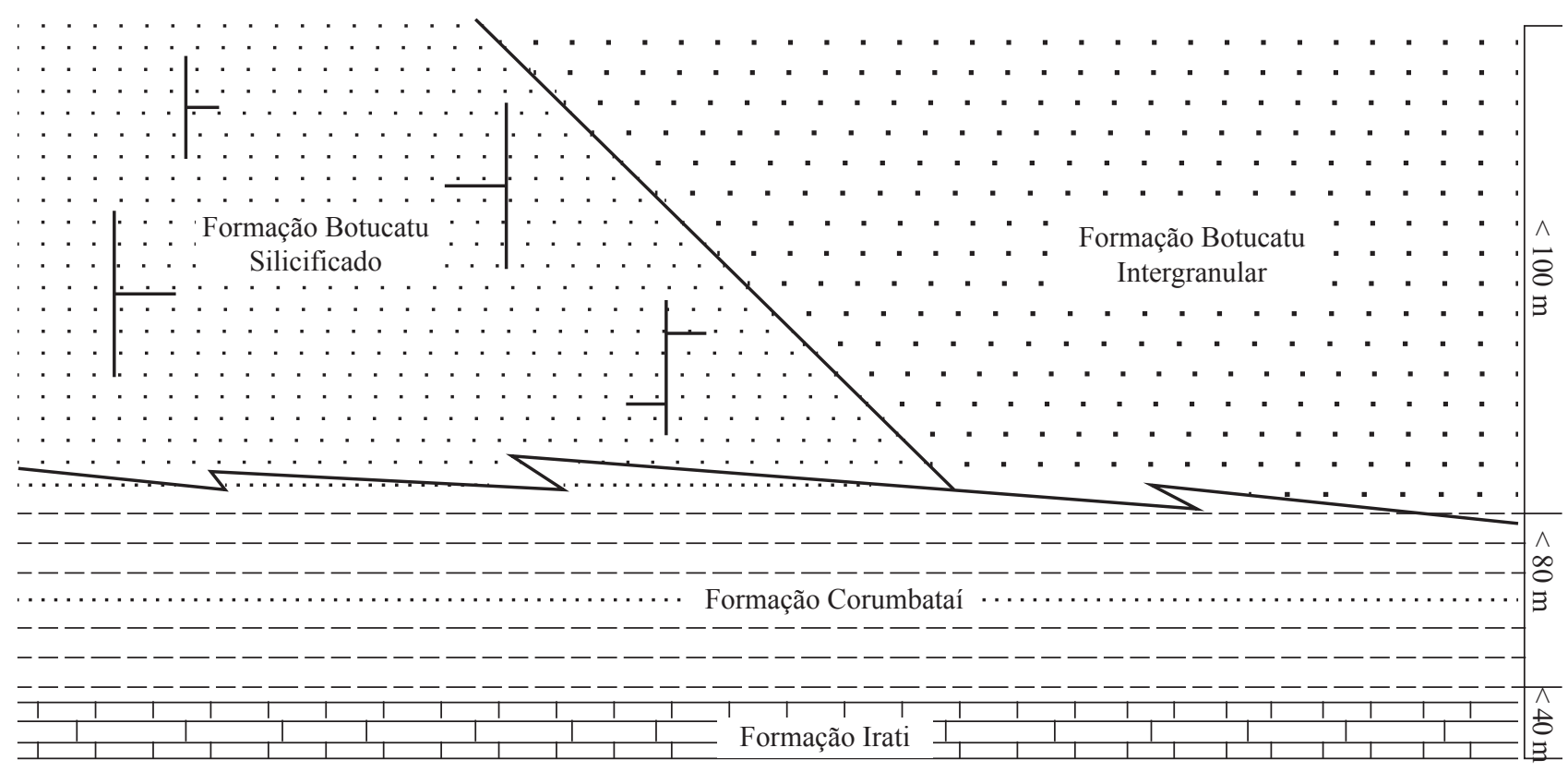

Figura 4 - Modelo conceitual do Sistema Aquifero Guarani (SAG) tipo livre de dupla porosidade que ocorre na região de Mineiros. Porção superior do desenho detalha sucessão lateral dos dois tipos de aquifero do SAG (Formação Botucatu) que ocorrem na região de Mineiros: lado esquerdo exibe arenito silicificado, assume comportamento de aquifero fraturado, no qual o detalhe da hachura indica planos de fraturas; lado direito exibe arenito poroso, assume comportamento de aquifero intergranular. Sotopostas à Formação Botucatu seguem as Formações Corumbatai e Irati.

Neste modelo, o aquífero é considerado homogêneo e anisotrópico e deve responder hidraulicamente ao método de Moench (1984), adaptado para sistemas livres ou modelos hidráulicos genericamente denominados de dupla porosidade. A modelagem do fluxo pode ser complexa, pois deve-se avaliá-lo na porosidade matricial ou primária residual e ao longo das fraturas que pode variar de laminar a turbulento.

Como o relevo apresenta padrão ondulado a forte ondulado e os solos são rasos a ausentes, a recarga é limitada, mesmo considerando se tratar de áreas de afloramento. Nas áreas associadas a este tipo de aquífero, a rede de drenagem superficial apresenta alta densidade e baixa vazão específica, o que é decorrente da própria limitação da recarga.

Os parâmetros hidrodinâmicos, neste setor, são sensivelmente menores quando comparados com os aquíferos livres homogêneos e isotrópicos das áreas de afloramento de Jataí. Desse modo, a condutividade hidráulica média é da ordem de $1,2 \times 10^{-5} \mathrm{~m} / \mathrm{s}$ e o coeficiente de armazenamento varia de 3,1 a 8,5 (Oliveira 2009). Da mesma forma que no caso do modelo de aquífero intergranular livre os argumentos para o enquadramento do modelo de fluxo foram basicamente as descrições de campo da geologia (superfície e subsuperfície) e o comportamento dos ensaios de bombeamento.
Do ponto de vista hidroquímico, estas águas são as menos mineralizadas da área de estudo, com valores de STD inferiores a $50 \mathrm{mg} / \mathrm{L}$. Apenas os poços que explotam águas do sistema misto Guarani/Corumbataí/ Irati apresentam maior mineralização, em grande parte devido ao aporte de íons de $\mathrm{Ca}^{++}$e $\mathrm{Mg}^{++}$resultantes da dissolução dos minerais calcita e dolomita, contidos nos calcários da Formação Irati. Como no caso dos aquíferos intergranulares livres, as águas são frias com temperaturas similares às médias da superfície.

Aquífero totalmente confinado Corresponde ao contexto em que os basaltos que recobrem os arenitos da Formação Botucatu apresentam espessuras maiores que $500 \mathrm{~m}$ e se encontram com baixo grau de fraturamento interconectado (Fig. 5). Assim, pode-se utilizar a região de Quirinópolis como o exemplo mais típico de área em que este modelo conceitual pode ser aplicado. Nesta área do aquífero, os derrames basálticos totalizam mais de 900 $\mathrm{m}$ de rochas pouco fraturadas e não falhadas.

Hidraulicamente, o conjunto deve responder aos métodos de Theis e Jacob (Theis 1935, Jacob 1950) para a determinação dos parâmetros dimensionais a partir dos dados de ensaios de bombeamento.

Os valores de transmissividade e coeficiente de armazenamento e condutividade hidráulica são $9,3 \mathrm{x}$ $10^{-4} \mathrm{~m}^{2} / \mathrm{s}, 3,8 \times 10^{-3}$ e $8,5 \times 10^{-6} \mathrm{~m} / \mathrm{s}$, respectivamente. 


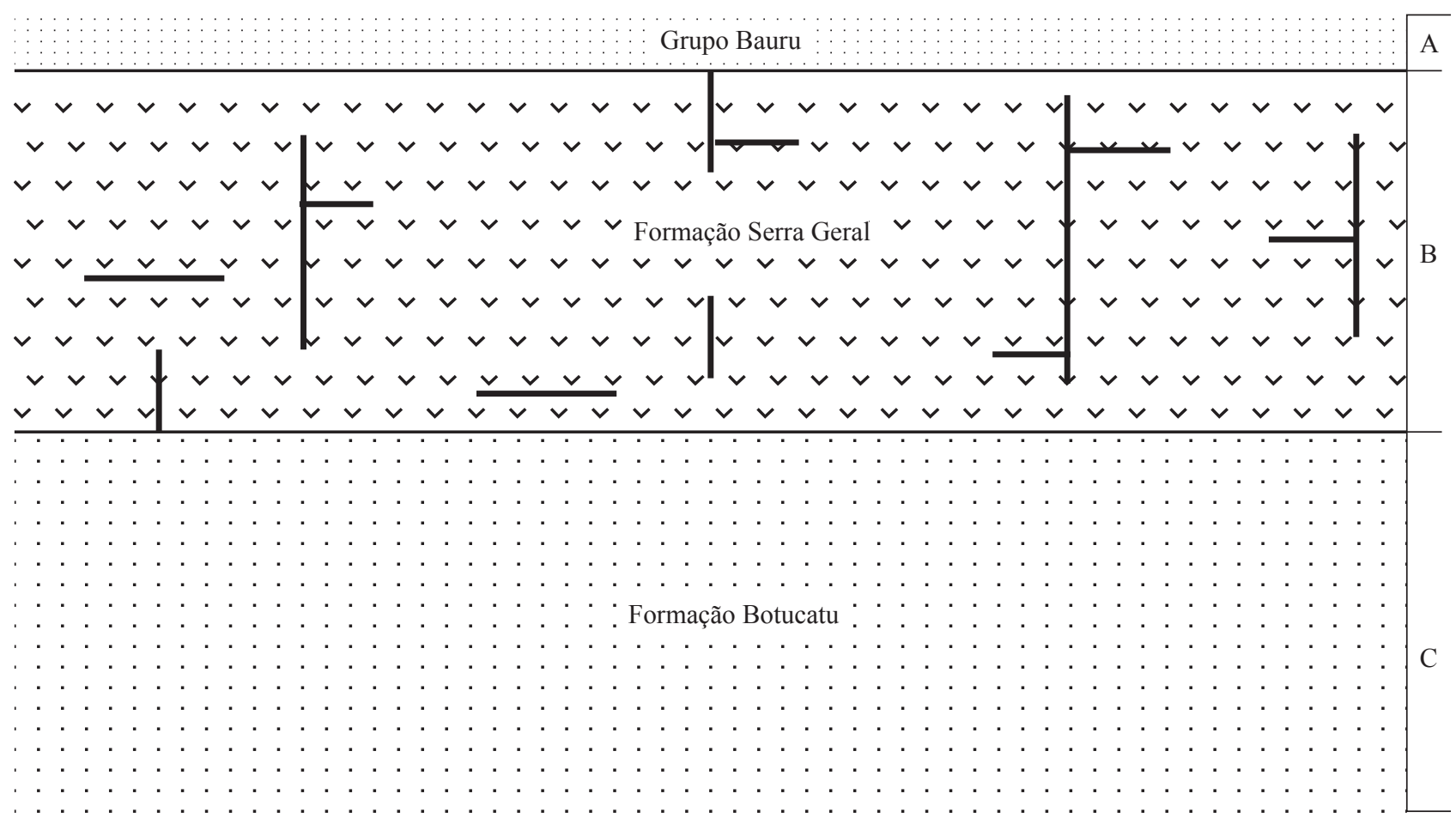

Figura 5 - Modelo conceitual de aquifero totalmente confinado que ocorre na região de Quirinópolis. (A) arenitos do Grupo Bauru, espessuras de até $80 \mathrm{~m}$; (B) camada confinante representada por derrames basálticos com espessuras entre 500 e 900 m e (C) Sistema Aquifero Guarani confinado (Formação Botucatu), espessura da camada arenitica entre 40 e $300 \mathrm{~m}$.

A relação entre a condutividade hidráulica dos basaltos e dos arenitos apresenta amplo contraste, o qual permite que as rochas vulcânicas funcionem como um aquífugo com relação aos arenitos. Mesmo considerando que os basaltos conformem um sistema aquífero independente (quando explotado isoladamente), o conjunto como um todo, principalmente a presença de derrames espessos e menos fraturados na porção central das camadas, compõe a camada confinante que funciona hidraulicamente como uma camada impermeável com relação aos arenitos.

Estudos específicos realizados a partir da descrição de sondagens rotativas para fins geotécnicos mostram que os basaltos apresentam-se intensamente intemperizados no contato com os arenitos. Tal situação inusitada é interpretada como uma alteração causada pela circulação da água dos arenitos na zona de contato. O material é similar ao saprolito observado na porção rasa dos furos, sendo composto por uma massa de argilominerais de tonalidade esverdeada ou arroxeada. Este material saprolítico deve ter um importante papel no confinamento das águas armazenadas nos arenitos da Formação Botucatu, de forma a inibir o fluxo ascendente ou descendente da água.
Neste caso, a base do aquífero é representada por unidades paleozoicas da Bacia do Paraná: material argiloso intemperizado da Formação Corumbataí, calcários da Formação Irati e, por fim, os arenitos de fácies variadas da Formação Aquidauana.

As águas apresentam temperaturas entre $44 \mathrm{e}$ $49^{\circ} \mathrm{C}$ o que é compatível com o grau geotérmico local. A mineralização das águas é intermediária quando comparada àquela das áreas de afloramento e de semiconfinamento e ainda às águas salinas da região de Cachoeira Dourada.

Levando-se em conta a estratigrafia abordada, a espessura dos derrames basálticos sobrepostos e os parâmetros hidrodinâmicos, é possível afirmar que hidraulicamente este sistema deve responder ao modelo de Theis para aquíferos intergranulares homogêneos e isotrópicos confinados na base e no topo por camadas impermeáveis (ou com amplo contraste de condutividade hidráulica em comparação com o aquífero).

\section{Aquífero semiconfinado sem contribuição de água de armazenamento do aquitarde É inter- pretado nas áreas em que as camadas confinantes da Formação Serra Geral apresentam espessura total infe- rior a $400 \mathrm{~m}$ e que os basaltos se encontram relativamen- te fraturados em derrames individuais pouco espessos.}


Essa condição permite que a água armazenada nos basaltos possa migrar por fluxo descendente e alimentar o aquífero sotoposto. Neste caso, o sistema Serra Geral representa uma camada confinante que funciona como um aquitarde e não como um aquífugo, pois o contraste de condutividade hidráulica é menor. Assim, a camada confinante representada pelos basaltos é sobreposta por um aquífero livre dos tipos homogêneo e isotrópico, representado por arenitos da Formação Adamantina e Marília do Grupo Bauru (Fig. 6). Essa situação ocorre na região Centro-sul da área de estudos.

É importante salientar que a água do aquitarde apenas migra por gotejamento e não há fluxo de contribuição a partir da água armazenada nos basaltos.

Este modelo conceitual deve responder ao de Walton para aquíferos semiconfinados (Walton 1962). Além da premissa de que o aquitarde alimenta o aquífero sotoposto por gotejamento, uma série de outras condições de contorno deve ser alcançada, como o aquífero confinado ser intergranular, ser confinado na base por um aquifugo, não ocorrer contribuição por água armazenada no aquitarde e o bombeamento no aquífero semiconfinado não afetar o aquitarde.
A área típica de ocorrência e funcionamento deste modelo conceitual é a porção do baixo rio Aporé na região de Lagoa Santa.

Além do contexto geológico, os dados hidroquímicos e os elementos sobre idade das águas são os principais argumentos para a proposição deste modelo de fluxo. A presença de águas bicarbonatadas cálcicas com moderada mineralização e, em muitos casos, com teores elevados de fluoreto são os principais argumentos. Desse modo, o teor alto de fluoreto é considerado como oriundo da dissolução de fluoritas comumente presentes em fraturas das fases tardimagmáticas dos basaltos e também encontradas em amídalas em associação com zeólitas, calcita, dolomita e sílica.

O resultado das datações por carbono 14 das águas na região de Lagoa Santa indica idades da ordem de $680 \pm 80$ anos antes do presente (AP). Considerando um regime de fluxo regional, com um gradiente da ordem de 0,002 , condutividade hidráulica média da ordem de $10^{-5} \mathrm{~m} / \mathrm{s}$ e porosidade eficaz de $10 \%$, a idade das águas deveria ser no mínimo de 3.170 anos AP (Oliveira 2009).

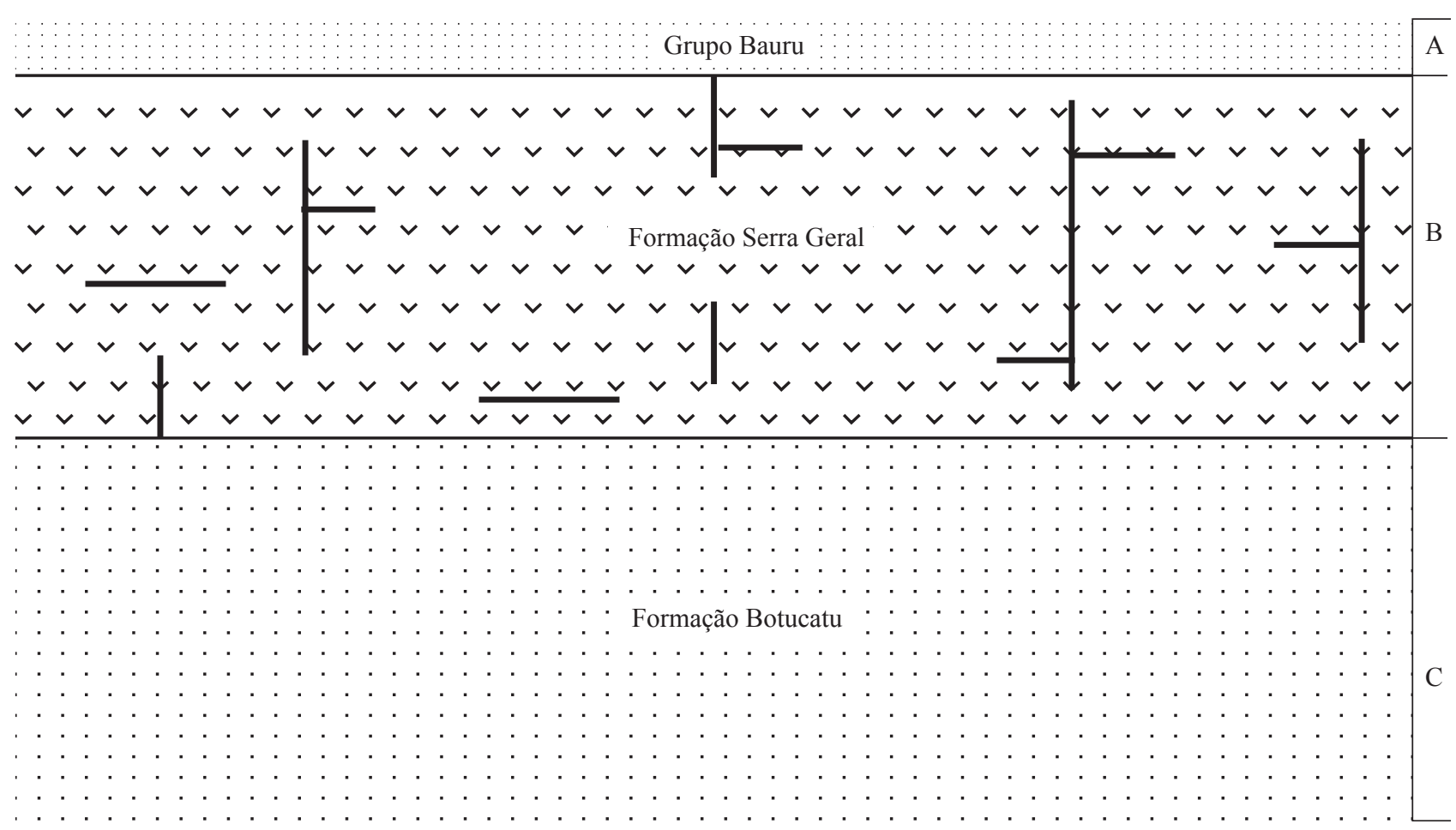

Figura 6 - Modelo de aquífero semiconfinado sem contribuição de águas armazenadas no aquitarde. $O$ gotejamento ocorre a partir de áreas em que os basaltos se encontram mais intensamente fraturados. (A) representa os afloramentos do Grupo Bauru, cujas espessuras são inferiores a $80 \mathrm{~m}$, (B) camada confinante de derrames basálticos da Formação Serra Geral, espessura inferior a $300 \mathrm{~m}$. Assume função de aquitarde, em que a drenança vertical da água subterrânea ocorre a partir das zonas de falhas e fraturas associadas, representadas no desenho pelas hachuras em negrito, (C) Sistema Aquífero Guarani semiconfinado (Formação Botucatu), espessuras máximas de $500 \mathrm{~m}$. Aquifero do tipo intergranular. Ocorre na região de Lagoa Santa. 
Mesmo considerando a possibilidade de infiltração a partir dos basaltos da Formação Serra Geral, é importante salientar que tal recarga ocorre por fluxo descendente lento, visto que análises de CFCs, quando realizadas em amostra do mesmo poço, não apresentaram nenhum destes gases. Esse dado mostra que não há recarga de águas mais jovens que 50 anos, porém não descarta a possibilidade de que águas contidas nos basaltos se misturem com aquelas de fluxo proveniente dos basaltos.

\section{Aquífero confinado com contribuição de água} armazenada no aquitarde Este modelo considera que águas armazenadas nos basaltos possam migrar em direção ao aquífero confinado sotoposto. Essa possibilidade é apenas plausível em áreas ao longo de grandes lineamentos que representam falhas com movimentação vertical considerável de grandes blocos. Ao longo dos falhamentos normais regionais, há a interligação das zonas fraturadas dos diversos derrames individuais, o que deve funcionar como uma zona preferencial de fluxo descendente (Fig. 7).
Do ponto de vista hidráulico, o fluxo descendente é apenas possível quando a carga hidráulica da coluna de água nos basaltos supera a carga potenciométrica de confinamento. Neste caso, haverá recarga a partir de água armazenada na camada confinante que passa a funcionar como um aquitarde, o qual contribui com água de armazenamento para o aquífero confinado.

Esta situação possivelmente não ocorrerá ao longo do plano dos lineamentos, mas apenas nas zonas em que o estresse (deformação rúptil) tenha sido mais amplo com a possibilidade de ampliação e interconexão das fraturas secundárias.

Hidraulicamente, o sistema deve responder ao modelo proposto por Hantush para aquíferos semiconfinados com contribuição de água de armazenamento (Hantush 1960). O parâmetro $\beta$ (fator de drenança) será função da condutividade hidráulica (grau de abertura e interconexão das fraturas) e do coeficiente de armazenamento dos basaltos e dos arenitos da Formação Marília, sobrepostos aos basaltos na porção centro-sul da área de estudos.

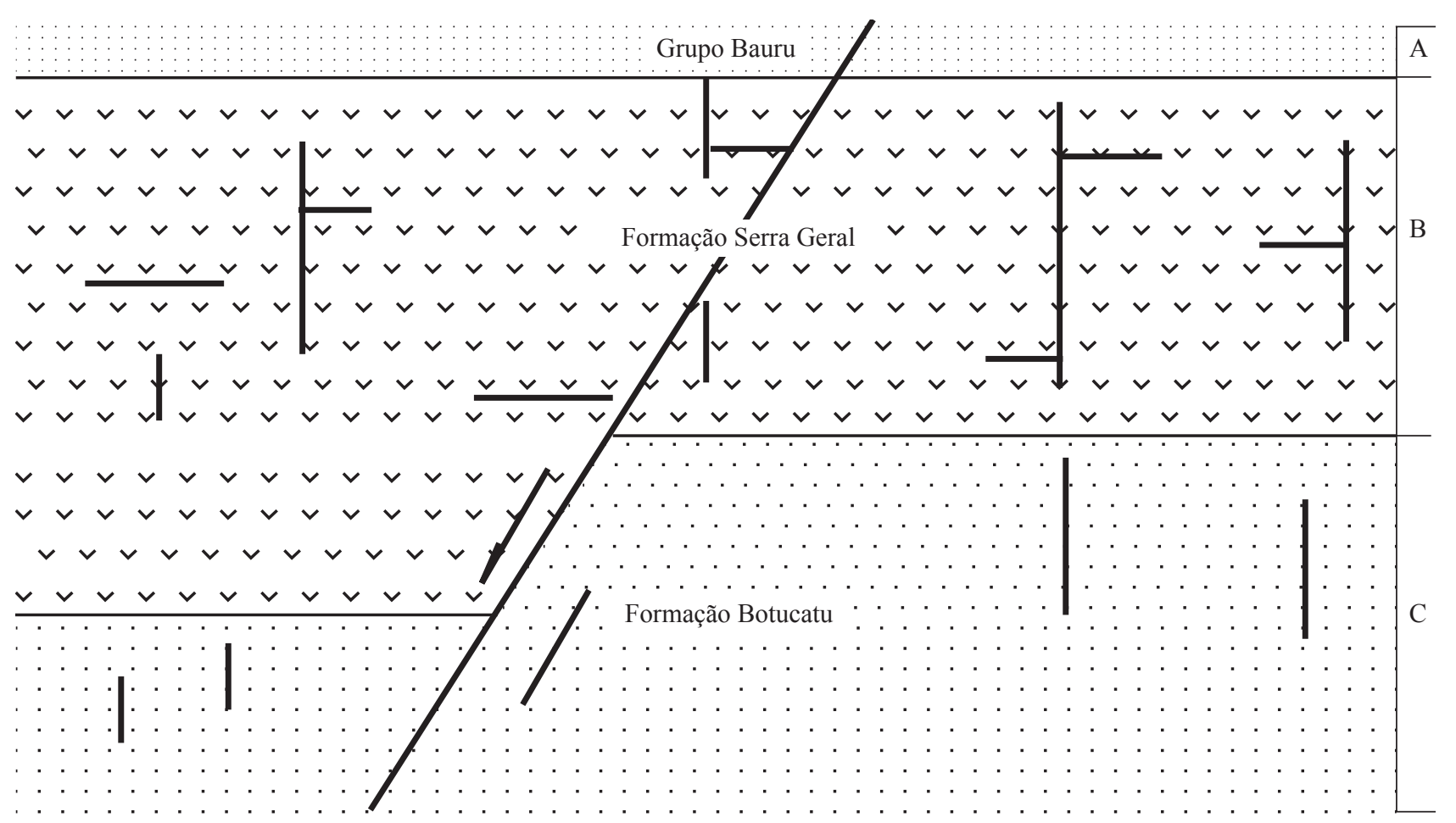

Figura 7 - Representação esquemática de aquifero semiconfinado com contribuição de água armazenada no aquitarde. A drenança vertical se dá a partir de zonas de falhas e fraturas associadas, presentes nos basaltos da Formação Serra Geral. (A) representa os afloramentos do Grupo Bauru, cujas espessuras são inferiores a $80 \mathrm{~m}$, (B) camada confinante de derrames basálticos da Formação Serra Geral com espessuras variando entre 350 e $500 \mathrm{~m}$. Detalhes das hachuras em negrito denotam os planos de fraturas e falhas, e (C) Sistema Aquifero Guarani semiconfinado (Formação Botucatu), espessura entre 100 e $300 \mathrm{~m}$. Aquifero intergranular. Os detalhes das hachuras em negrito denotam os planos de falhas no pacote arenítico. Ocorre na região de Cachoeira Dourada. 
Os argumentos que suportam esta hipótese de modelo de fluxo são basicamente a hidroquímica e os dados isotópicos. Valores de fluoreto muito elevados em águas do Aquífero Guarani, em amostras de água obtidas de poços, cuja seção de basaltos foi eficientemente isolada, são dados considerados importantes no sentido de corroborar a hipótese. Na região de Cachoeira Dourada de Goiás foram relatados valores de $\mathrm{F}^{-}$maiores que $1 \mathrm{mg} / \mathrm{L}$, sendo que na maior parte dos casos as águas do Sistema Guarani nas áreas de confinamento apresentam valores menores que $0,4 \mathrm{mg} / \mathrm{L}$. Como considerado por outros autores (Bittencourt et al. 2003) para o estado do Paraná, os valores anômalos são atribuídos à mistura das águas dos sistemas Guarani e Serra Geral ao longo de zonas e falhas.

A idade de circulação mais antiga que 40.000 anos indicando fluxo lento e a posição ocupada pela região de Cachoeira Dourada, margem da Bacia Sedimentar, distante apenas $15 \mathrm{~km}$ do embasamento cristalino, permitem inferir que a água do Aquífero Guarani nessa região é proveniente de recarga indireta, via basalto, confirmando a existência de um fluxo semiestagnado para oeste, sentido DTRP.

Outro fato que corrobora com essa proposta é o controle local na carga hidráulica dos poços. $\mathrm{Na}$ possibilidade da existência de um fluxo mais regional, integrando as porções oeste (áreas de recarga e fluxo principal) e leste do aquífero (zona de alto grau de confinamento de Quirinópolis e região de Cachoeira Dourada), o gradiente potenciométrico entre as regiões justificaria jorro nos poços de Cachoeira Dourada, o que não é verificado. Situações de artesianismo jorrante somente ocorrem na cidade de Cachoeira Dourada, posicionada numa faixa tectonicamente deprimida no vale do Rio Paranaíba (cota de $410 \mathrm{~m}$ ), não ocorrendo no poço perfurado na Usina Cachoeira Dourada, que se encontra em cota altimétrica de $460 \mathrm{~m}$, distante apenas $25 \mathrm{~km}$ da cidade, sentido oeste, em direção a DRTP. No referido poço, a carga hidráulica não é suficiente para promover condições de jorro, de forma que a superfície potenciométrica permanece abaixo da superfície do terreno.

Neste sentido, comparando os valores do potencial de óxido-redução das águas da porção leste do aquífero, verifica-se que estas são as mais redutoras do Sistema Aquífero Guarani no estado, sendo que os valores decaem de $-43 \mathrm{mv}$, em média, na região de Cachoeira Dourada, para valores mínimos de
-92 mV em Quirinópolis. Este fato reforça a evidência da existência de um fluxo alimentado por recarga indireta, originado em Cachoeira Dourada.

CONCLUSÕES A determinação do modelo de fluxo mais próximo ao real é fundamental para a gestão adequada do aquífero e para a definição de seu potencial quantitativo. Por exemplo, caso o aquífero responda de forma prioritária ao modelo do tipo totalmente confinado, a recarga será limitada e grande parte da água armazenada poderá ser considerada como sendo de fluxo semiestagnado ou de recarga muito lenta, o que deve diminuir a importância do reservatório. Por outro lado, no caso de parte do sistema responder ao modelo de semiconfinamento com contribuição de água de armazenamento do aquitarde, o potencial é imediatamente ampliado. Mesmo nas áreas de recarga, onde o sistema é livre, seu potencial deverá ser distinto nos casos em que o aquífero é intergranular ou do tipo dupla porosidade.

A proposição mais precisa dos modelos conceituais de fluxo para o Aquífero Guarani no estado de Goiás será fundamental para a evolução dos estudos, que incluam a modelagem matemática, pois para a solução correta dos modelos numéricos as condições de contorno representam uma fase vital para se alcançar resultados confiáveis.

Para a determinação da distribuição areal dos vários modelos de fluxo propostos, será necessária a ampliação do acervo de dados incluindo informações geofísicas (para a determinação das espessuras e rejeitos de falhas), hidroquímicas (para o enquadramento dos tipos químicos), isotópicas (para a datação das águas) e de ensaios de bombeamento em um número mais expressivo de poços totalmente penetrantes.

No estado de Goiás o Sistema Aquífero Guarani é integrado por diferentes subsistemas que respondem a cinco possibilidades de modelo conceitual de fluxo em diferentes áreas de ocorrência, sendo: aquífero intergranular livre, presente na área de Jataí; aquífero de dupla porosidade livre, na região de Mineiros; aquífero totalmente confinado que ocupa a maior porção em que os basaltos estão sobrepostos aos arenitos do Grupo Bauru; aquífero semiconfinado sem contribuição de água do aquitarde, distribuído na região de Lagoa Santa; aquífero semiconfinado com contribuição de água armazenada no aquitarde (considerado como presente na região de Cachoeira Dourada de Goiás). 
Os argumentos para a proposição dos diversos modelos incluem: geologia de superfície e de subsuperfície, dados hidroquímicos, concentrações de isótopos estáveis e de CFCs e idades das águas.

A aplicação dos modelos de fluxo coerentes nos diversos compartimentos tectônicos e nas diferentes áreas de ocorrência é fundamental para o desenvolvimento do conhecimento sobre o aquífero. A modelagem matemática dos sistemas é tanto mais ajustada, quanto mais adequado for o modelo conceitual de fluxo adotado. O modelo conceitual de fluxo também é a principal condição de contorno para a quantificação da recarga do aquífero, para a determinação do potencial do sistema e para sua gestão apropriada.

AGRADECIMENTOS Os autores agradecem ao Conselho Nacional de Desenvolvimento Científico e Tecnológico pela concessão de financiamento via projeto de pesquisa CNPq 474453/2006-5, sem o qual não seria possível a realização deste trabalho.

\section{Referências}

Almeida L., Resende L., Rodrigues A.P., Campos J.E.G. 2006. Hidrogeologia do Estado de Goiás e Distrito Federal. Superintendência de Geologia de Mineração, Governo de Estado de Goiás. 230p.

Araújo L.M., França A.B., Potter P.E. 1995. Aquífero gigante do Mercosul - Brasil, Argentina, Uruguai e Paraguai: mapas hidrogeológicos das Formações Botucatu, Pirambóia, Rosário do Sul, Buena Vista, Misiones e Tucuarembó. Curitiba, UFPR/ PETROBRÁS.

Bittencourt A.V.L., Rosa Filho E.F., Hindi E.C., Filho A.C.B. 2003. A influência dos basaltos e de misturas com águas de aquíferos sotopostos nas águas subterrâneas do Sistema Aquífero Serra Geral na bacia do Rio Piquiri, Paraná - BR. Revista Águas Subterrâneas, 17:67-75.

Dias C.L., Silva M.F.B., Casarini D.C.P., Lemos M.M.G. 2002. Caracterização hidrogeoquímica e qualidade do Sistema Aquífero Guarani em poços tubulares para abastecimento público no estado de São Paulo. In: CONGRESSO BRASILEIRO DE ÁGUAS SUBTERRÂNEAS, 12. Florianópolis. Anais... São Paulo: Associação Brasileira de Águas Subterrâneas. 1 CD.

Gastmans D. 2007. Hidrogeologia e hidroquímica do Sistema Aquífero Guarani na porção ocidental da Bacia Sedimentar do Paraná. Tese (Doutorado em Geociências), Instituto de Geociências e Ciências Exatas, Universidade Estadual Paulista "Júlio de Mesquita Filho", Rio Claro, 194 p.

Gastmans D. \& Kiang C.H. 2005. Avaliação da hidrogeologia e hidroquímica do Sistema Aquífero Guarani (SAG) no estado de Mato Grosso do Sul. Revista Águas Subterrâneas, 19(1):35-48.

Hantush M.S. 1960. Modification of the theory of leaky aquifers, Journal of Geophysical Research, 65(11):3713-3725.
Jacob C.E. 1950. Flow of groundwater. In: Rouse E.H. Engineering Hydraulics. New York, John Wiley, p. 321-386.

Moench A.F. 1984. Double-porosity models for a fissured groundwater reservoir with fracture skin. Water Resources Research, 20(7):831-846.

Neuman S.P. 1972. Theory of flow in unconfined aquifers considering delayed response of the water table. Water Resources Research, 8(4):1031-1045.

Neuman S.P. 1975. Analysis of pumping test data from anisotropic unconfined aquifers considering delayed yield. Water Resources Research, 11(2):329-342.

Oliveira L.A. 2009. O Sistema Aquífero Guarani no estado de Goiás: distribuição, caracterização hidrodinâmica, hidroquímica, composição isotópica e CFCs. Tese (Doutorado em Geologia), Instituto de Geociências, Universidade de Brasília, 188 p.

Rocha G.A. 1996. Mega reservatório de água subterrânea do cone sul: bases para uma política de desenvolvimento e gestão. In: Seminário Internacional Aquífero Gigante do Mercosul, 1., 1996. Curitiba. Anais ... Universidade Federal do Paraná, Curitiba.

Rosa Filho E.F. 2004. Fatores controladores $d a$ hidrodinâmica do Sistema Aquífero Guarani no estado do Paraná. Curitiba: Relatório de Pesquisa CT/ HIDRO. Universidade Federal do Paraná, 49 p.

Theis C.V. 1935. The relation between the lowering of the piezometric surface and the rate and duration of discharge of a well using groundwater storage. Transactions - American Geophysical Union, 16:519-524.

Walton W.C. 1962. Selected analytical methods for well and aquifer evaluation. Illinois State Water Survey Bulletin, 49.

Manuscrito ID 16367

Recebido em: 12/12/2009 Aprovado em: 07/08/2012 